\title{
Interconnecting Product and Manufacturing Domains: A Literature Review
}

\author{
Paraskeva WLAZLAK ${ }^{\mathrm{a}, 1}$, Ann-Louise ANDERSEN ${ }^{\mathrm{a}, \mathrm{b}}$, Dag RAUDBERGET ${ }^{\mathrm{a}}$ \\ ${ }^{a}$ Department of Industrial Product development, Production and Design, Jönköping \\ University, Sweden \\ ${ }^{b}$ Department of Materials and Production, Aalborg University, Denmark.
}

\begin{abstract}
Research on product-process modelling has been significant over the last decade. In this paper, we present a literature review of 13 papers published in journals and conference proceedings between 2012-2019. The purpose of this paper is to review and classify the literature on integrated product-process modelling utilizing ontologies. Specifically, the objectives of the paper are; (1) to develop a classification framework that is based on the existing research on integrated product-process modelling; (2) to use the classification framework to synthesize what is known in this research area (qualitative issues that have been raised that are useful for both researchers and practitioners); (3) to use the classification framework to propose future avenues in this research area. The classification framework consists of three major categories; namely, (1) integrated product-process model's application; (2) approaches to modelling; and (3) practical challenges for implementation of integrated product-process models. The classification of the published literature and the analysis provides insights for practitioners and researchers on the creation and accumulation of knowledge in the product-process modelling area and interconnecting of product and manufacturing domains. This paper is intended to highlight the importance of integrated productprocess models utilizing ontologies and identify areas for future research areas.
\end{abstract}

Keywords. Academic literature review, Product-process models, Ontologies, Classification framework

\section{Introduction}

The topic of the paper is integrated product-process modelling. This topic has attracted attention of researchers and practitioners alike due to the need of interconnecting the product and manufacturing domains [1]. This is in response to trends for manufacturing companies in terms of product customization, short time-to-market and rapid technology development.

In practice, it is often the case that small changes in a product cause large and unexpected effects in the manufacturing system. The opposite is also true; introducing changes in a manufacturing system can cause large and unexpected effects on the products that can be offered to the customers. That is why, interconnecting product and manufacturing domains is an exciting research area that is continuously growing.

\footnotetext{
${ }^{1}$ Corresponding Author. paraskeva.wlazlak@ju.se
} 
Likewise, related concepts such as co-evolution of products, processes and systems have been coined to describe a desired situation where changes in each domain corresponds to changes in the other domains in a foreseeable way and where unnecessary ripple effects are avoided which eventually can create increased competitiveness for companies in volatile markets $[2,3,4]$.

Realising such interconnection in practice requires understanding and management of the relations and interactions between the product characteristics and manufacturing systems. One way to do that is by using formal models that represent both variety of products and manufacturing processes. In the literature there exists a number of product-process modelling approaches [1]. Some researchers focus on development of integrated product and manufacturing methodologies [5] and conceptual formal models [6]. Other researchers focus on establishing integrated product-process models by utilizing ontologies enabling links and collaboration between the product and manufacturing domains [7]. Formal engineering ontologies are solution to address the interoperability between the product and the manufacturing domains. Gruber [8] defines ontology as formal specification of a shared conceptualization. Conceptualization is an abstract model of some phenomenon including the key concepts of this phenomenon [9]. Ontologies consist of classes that provide formal, structured representation of important things in the reality, the relationships between the classes, as well as the properties that provide details for each class and the respective limitations.

This paper focuses on integrated product-process models utilizing ontologies. To continue the advancement of knowledge in the integrated product-process modelling area, it is important to understand the current status of the research and to examine contemporary trends. It is vital to determine the principle concerns of the current research, whether they are related to the difficulties faced by companies, application, motivation and benefits of interconnecting the domains. Although emerging studies examine parts of the research, an academic overview of the literature has thus far been lacking.

The purpose of this paper is to review and classify the literature on integrated product-process modelling utilizing ontologies which was published between 20122019. Specifically, the objectives of the paper are;

(1) to develop a classification framework that is based on the existing research on integrated product-process modelling;

(2) to use the classification framework to synthesize what is known in this research area (qualitative issues that have been raised that are useful for both researchers and practitioners);

(3) to use the classification framework to propose future avenues in this research area.

This will aid the research on integrated product-process modelling by providing insights for practitioners and researchers on the creation and accumulation of knowledge in this area. In other words, it will help to answer the questions what we know and what we do not know in this area. This paper is intended to highlight the importance of integrated product-process models utilizing ontologies.

\section{Research methodology}

The purpose of the paper is to review and classify the published literature on integrated product-process modelling. In order to restrict the search to more recent 
publications, the time frame for this study was chosen initially to include only literature published between 2012-2019. This eight-year period is representative of the published literature on the topic.

To achieve the purpose of the literature review, this research covers various publications including journals and conference papers, all of which are related to integrated product-process modelling. The search strategy used a range of keyword combinations including e.g. production, product, modelling. The following search strings were used in the various databases.

- (manufactur* OR production) AND product AND model* AND ontolog*

- $\quad$ process AND product AND model* AND ontolog*

- co-develop* OR co-evol* OR co-platform*

In total, we identified 13 published papers for the period of 2012-2019 that were published in 4 journals and 5 conference proceedings. The titles were then checked to ensure relevance to the review. Abstracts of all papers were reviewed before selecting publications for a full review. Each published paper retrieved through the search process was carefully reviewed before taking a decision regarding its inclusion in the literature overview. Researchers agreed on the categories included in the classification framework and on the division of the relevant publications according to the categories.

\section{Classification framework}

The framework includes a content-oriented classification of the integrated productprocess modelling literature. The classification framework comprises three major categories; namely, (1) integrated product-process model's application; (2) approaches to modelling; and (3) practical challenges for implementation of integrated productprocess models. The details concerning the main categories and the scheme are presented in the next section.

\subsection{Integrated product-process model's application}

The literature in this category is divided into several sub-categories that reflect the benefits associated with integrated product-process models. These sub-categories define the goals of the ontologies and the areas of application. These sub-categories describe what the models using ontologies should support and their intended use.

\subsubsection{Support co-platforming and changeable manufacturing systems}

Integrated product-process models are associated with the research stream of coplatforming or co-evolution, where solution space of products is matched to the capabilities of the manufacturing system and vice versa [10;11]. Co-developing platforms or co-evolving of formal representation or documentation of products and manufacturing system help product developers to develop solutions based on the platforms. It is further argued that integrated product-process models are beneficial when designing, managing and operating changeable production systems [10]. Integrated models can be applied to enhance production/assembly system reconfigurability as well as transformability [1;12]. Additionally, co-platforming represents a rather well-established research stream focusing on how to quantitatively 
determine platform and non-platform machines in the manufacturing domain while at the same time determining platform and non-platform features in the product domain e.g. through matrix manipulation or optimization approaches $[13 ; 14 ; 15 ; 16]$.

\subsubsection{Control butterfly effects}

By integrating product and manufacturing information in an integrated model, manufacturing information can improve the product configuration process, as well as the product configuration information can support the manufacturing process [11]. In [17] and [18] the authors aim to support unified definition and dynamic evolution and sharing of data in the manufacturing process as well as integration with other systems. In addition to models using ontologies, some researchers propose other approaches to modelling the information from the product and manufacturing domains. AlGedawwy and ElMaraghy [19] proposed cladistics as an approach for establishing and comparing evolution and changes in products and corresponding manufacturing capabilities. The cladogram can potentially highlight similarity between the two domains which can be used as information guiding future planning of products and production development projects. Michaelis and Johannesson [20] likewise addressed how different paradigms for platform-based product and production development can support co-evolution and enable more efficient handling of frequent changes in the product domain. Various types of modelling techniques are addressed as support for this, e.g. generic bill of materials, extended product family master plan, and function means trees.

\subsubsection{Support product design phase}

Integrated models can support design projects, where information relevant in the product design phase when design for manufacturing activities are carried out may be depended on the capabilities of the existing equipment. The method presented in [21] aims at identification of past similar products and their production processes and speed up the design for manufacturing of a new product. Manufacturing constraints are taken early in the product design phase where integrated models can provide clear and timely design recommendations to designers during the design process. The benefits are also associated with reduced interactions of design changes between designers and manufacturing engineering, as well as reduced time for product design process [22]. Additionally, to the integrated models utilizing ontologies some researchers present methodologies for to the integration of information from the product and manufacturing domains.

\subsubsection{Support production planning and scheduling}

Information represented in the models can be used for optimization of production planning, where possible combinations of components and production processes are known [11]. Integrated product-process models have the potential to support decisions regarding changeability (e.g. calculate timing and cost for different sequences of product combination, optimize production sequence); and flexibility (decide on the routes for a product), cost for alternative routes can be calculated [7; 10]. In [22] and [17], the authors argue that integrated models can facilitate manufacturing process planning. In [24], the authors support the effective use of product design information and knowledge generated from the product model facilitate the decision-making of an assembly sequence by providing feasible product relations. Based on the knowledge 
representation proposed in [18], the research on the intelligent process planning and decision making will be carried out.

\subsection{Practical challenges for implementation}

Limited research is devoted to integrated product-process modelling, where relations and interactions between the product and the manufacturing domains are well established [11]. In general, the prior research is mainly devoted to product modelling. Based on the various challenges featured in the reviewed published papers, we divide this category into two sub-categories.

\subsubsection{Lack of systems integration}

Research indicates great potential for integrated product-process models, however, implementation of such models in practice is difficult due to lack of systems integration between the domains [11]. Some papers $[12 ; 25]$ argue that product, manufacturing process, and resource information exist within a company, but the information is often not effectively coupled. Some papers $[17 ; 24]$ argue that different information systems typically reflect different stages of the product life cycle and it is difficult to exchange data between them. Different information systems express for example product's attributes using terms meaning the exact same concept or use the exact same term to mean very different concepts and hence difficult to integrate information between systems. In [25], the author mention that integration methods or tools to map information across the product realisation domains are lacking. Depending on the domain engineers use different terminologies and perceive the overall development objective from different perspectives. This typically result in various documentation which due to inconsistent descriptions across the domains interconnecting of information is difficult [25].

\subsubsection{Information retrieval and reuse}

Several manufacturing classifications, taxonomies and ontologies exist, however, these often include too many processes and the related capabilities include too many details which complicate the development of integrated models [11]. Some authors $[12 ; 21]$; argue that companies are often unaware of the extent of manufacturing knowledge and relevant information from previous similar projects. Information retrieval and reuse is inefficient in many companies where product developers spend around $20 \%$ of their time in searching and analysing personally stored information. In [22], the authors argue that product designers often lack in-depth knowledge of manufacturing, and therefore design of high-quality products is inefficient. Many time-consuming iterations of design changes are required between designers and manufacturing engineers [25]. The authors in [18] add that representing manufacturing knowledge requires extensive knowledge of various processes in order to select them and carry out process planning. Most of the manufacturing process knowledge remains in the minds of experience engineers, and engineering handbooks [25]. In addition, many advanced manufacturing technologies are constantly emerging. In this regard, it is difficult to give all manufacturing processes a unified description and knowledge representation. The authors in [25] mention that in industrial settings the product and the manufacturing models generated are often not used or updated. 


\subsection{Approaches to modelling}

The literature in this category is divided into several sub-categories in accordance to the proposed approaches to integrated product-process modelling and the key concepts on which the models focuses. Some of the developed models are validated in a real-life context while others remain conceptual.

\subsubsection{Ontology for modelling product, production process and equipment (conceptual)}

Researchers $[1 ; 10 ; 11 ; 26]$ propose approach to model product platform and manufacturing platform based on a meta model. The meta model describes the structure of a company specific ontology covering general types of production processes and types of components. The model also describes the relations between the company specific ontologies and the observable instances in product and manufacturing portfolio. The main classes included in the company specific ontology are 1) 'component type' this class represent component types from the product portfolio with similar characteristics or manufacturing using the same process type; 2) 'characteristic definition' - this class describes the components; 3) 'process type' - this class represent types of production processes which perform the same operations on a workpiece (e.g. welding, milling, casting); 4) 'capability definition' - this class represent the functions that can be performed and the attributes by which the process is characterized; and 5) 'equipment type' - this class represent the resource that is needed to release a certain process. Furthermore, the ontologies specify the relations between the components characterises and process capabilities.

In [27] the authors develop a model where the production process is presented using a black box, which includes input/output flows as well as the core of the black box - the operation. Operations are further represented by equipment, tools, workpiece (i.e. object to be manufactured) and the related object's features. The ontology classes for the model include: 1) 'process' class - it describes the individual production operation for material or semi-finished parts to be manufactured; 2) inflow and outflow classes for each production operation; 3) 'equipment and tool class', 4) workpiece and feature class - it describes the input material of a unit process and the object to be processed; and 5) 'manufacturing capability class'.

\subsubsection{Ontology for modelling product, production process and equipment (real-life case)}

In the paper [22], the authors propose ontology to represent the knowledge of product and its features as well as production process. They express constraint knowledge by using rules to represent relations between the products' features and the production processes. The authors develop an ontology-based product design framework that consists of three layers: 1) foundation layer; 2) domain layer; and 3) instance layer. The foundation layer contains the core product model (CPM) and the Standard for the Exchange of Product model data (STEP) and Ontology Web Language (OWL). This layer defines the general concepts, as well as the relationships and the restrictions for the entire framework. The domain layer contains product design and manufacturing ontology, as well as mapping between them and their related semantic rules. The last layer is the instance layer consisting of an inference engine for performing ontology reasoning. 


\subsubsection{Ontology for modelling product, production and assembly processes (conceptual)}

In [7] the authors develop a conceptual model of the relations between the product requirements, resources and capabilities. The idea is that the model provides a processoriented definition of capabilities which allow the matching of product processing requirements with the resource capabilities. The authors focus on development of capability model ontology including both domains production processes and assembly processes, as well as development of resource model ontology. The main classes of the capability model are the capability (the parent class) and the capability parameter. The capability name indicates the name of the capability such as 'moving', 'drilling', whereas the capability parameter represent the characteristic of the capability such as 'speed', 'acceleration'. The capability model distinguishes between simple and combined capabilities.

In [21] the authors focus on representing the new product by the list of classes of the ontology representing the processing and assembly operations required by the new product. This method allows for reuse of product solutions and the related production operations (processing and assembly) for design of new products. They include a framework for semantic similarity computation with prior products and the related production operations, where the similarity is computed by using a semantic manufacturing model in the form of ontology. The model includes hierarchical organisation of different classes related to main class of processing operation and assembly operation, which are divided further into subclasses. This allow for building of manufacturing process ontologies.

In [12] the authors propose an approach for mapping the requirements needed for manufacturing products in assembly lines based on ontology model. The modelling approach for product, process and resource mapping for assembly automation domain includes three classes that allow the physical concepts description of the assembly line: 1) system - this class is used for assembly line instances; 2) station - this class represent different stations of the system; and 3) component - this class represent elements that are needed to perform station operations. The model contains three classes that allow the process related descriptions: 1) operation - this class describes operations carried out in stations; 2) process - this class represents processes linked to operations; and 3) task - this class includes tasks of processes. Product class represents the type of products that are manufactured in the assembly line. Resources represent machine units at different levels component, station or cell. Each resource supports a specific process.

In [24], the authors present an ontology model of assembly operation considering 'product geometry'. The ontology model depicts the terminology and data structure for assembly sequence planning. Classes included in the ontology model for assembly sequence planning are 1) assembly structure - this class describes the structure information of the assembly from product design to assembly process planning; 2) assembly process - this class describes information that connects assembly structure, assembly resources and other information in logical and time-sequenced way; 3) assembly position and orientation - this class describes aspects of assembly process planning such as relative positioning of parts and assembly path planning which depend on the position and orientation of parts and components; 4) assembly entity geometry- this class describes detailed geometric information of the product, part and component. 
In [18], the authors model products which are realised by processes. In turn these production processes consume resources and requirements. To model the interdependencies and predict the impact of the changes there is a need to understand the production process, resources and requirement implications of product changes and vice versa. Product data is linked to process and resource data.

\subsubsection{Ontology for modelling product, production and assembly processes (real-life case)}

In [25], the authors focus on three domains, namely product, process and resource domains and the links across the domains. Product domain describes the product components with respect to the assembly they form and the relationships that exists between components and assemblies. Process domain focuses on operation, process and tasks. While the resource domain consists of; 1) non control components, i.e. components that do not need control such as fixtures but have important function for the product realisation; 2) process component describes the sequence in which actuators should act based for examples on inputs from sensors; 3) sensor include all the sensors in the system; 4) control component focus on components that are controlled such as actuators or robot.

\subsubsection{Ontology for modelling product life cycle (conceptual)}

From a product lifecycle aspect, in [17] the authors present ontology-based manufacturing information that describes the information related to the product design result, process planning, materials quota and manufacturing. The model concerns the resources and information with respect to the manufacturing process. It includes the product itself, the plant where the product is to be manufactured, process information that describes the procedures and sequences of products, physical resources, and their relations.

\section{Classification results}

A total of 13 papers on integrated product-process modelling utilizing ontologies were classified according to the classification framework. Additionally, papers describing other conceptual models were mentioned for comparison but not included in the classification results.

\subsection{Distribution of papers by year of publication}

The distribution of published papers by year of publication from 2012 to 2019 is presented on Figure 1.



Figure 1 Distribution of papers by year of publication 


\subsection{Distribution of papers by journal and conference}

Our results include a total of 4 journals from various disciplines as well as a total of 5 conference proceedings. Table 1 lists the journal and conference papers on the integrated product-process models utilizing ontologies during 2012-2019, as well as the number of papers identified in each journal or conference.

Table 1 Journal and conference papers

\begin{tabular}{ll}
\hline Journal & No. of papers \\
\hline International Journal of Production Research & 1 \\
Journal of Intelligent Manufacturing & 1 \\
International Federation for Information Processing & 1 \\
International journal of Advanced Manufacturing Technology & 3 \\
\hline Conference and Conference proceedings & No. of papers \\
\hline Procedia CIRP & 3 \\
IEEE International Conference on Automation Science and Engineering (CASE) & 1 \\
IEEE International Conference on Industrial Informatics & 1 \\
International Conference on Computer Supported Cooperative Work in Design & 1 \\
International Conference on Industrial Engineering and Systems Management (IESM) & 1 \\
\hline
\end{tabular}

\subsection{Distribution of papers by topic}

Table 2; Table 3 and Table 4 list the number of papers related to the three major categories of the classification framework: 1) integrated product-process model's application; 2) practical challenges for implementation and 3) approaches to modelling; and the respective sub-categories. The number of papers related to each sub-category and the percentage by sub-category is also indicated in the tables.

Table 2 Number of papers related to category: integrated product-process-model's application

\begin{tabular}{lllll}
\hline $\mathbf{N}$ & Sub-category & $\begin{array}{l}\text { Number of } \\
\text { articles }\end{array}$ & $\begin{array}{l}\text { Percentage } \\
\text { by sub- } \\
\text { category }\end{array}$ & Reference \\
\hline 1 & $\begin{array}{l}\text { Support co-platforming and } \\
\text { changeable manufacturing systems }\end{array}$ & 5 & $29,41 \%$ & {$[1][7]$} \\
2 & $\begin{array}{l}\text { Control Butterfly Effects } \\
3\end{array}$ & 3 & & {$[10][11][12]$} \\
4 & Support product design phase & 2 & $17,64 \%$ & {$[11][17][18]$} \\
& $\begin{array}{l}\text { Support production planning and } \\
\text { scheduling }\end{array}$ & 7 & $11,76 \%$ & {$[21][22]$} \\
& Total & 17 & $41,17 \%$ & {$[7][10][11][17]$} \\
\hline
\end{tabular}

Table 3 Number of papers related to category: practical challenges for implementation

\begin{tabular}{lllll}
\hline $\mathbf{N}$ & Sub-category & $\begin{array}{l}\text { Number of } \\
\text { articles }\end{array}$ & $\begin{array}{l}\text { Percentage } \\
\text { by sub- } \\
\text { category }\end{array}$ & Reference \\
\hline 1 & Lack of systems integration & 5 & $45,45 \%$ & {$[11][12][17][24]$} \\
& & & & {$[25]$} \\
2 & Information retrieval and reuse & 6 & $54,54 \%$ & {$[11][12][18][21]$} \\
& Total & 11 & $\approx 100 \%$ & {$[22][25]$} \\
\hline
\end{tabular}


Table 4 Number of papers related to category: approaches to modelling

\begin{tabular}{|c|c|c|c|c|}
\hline $\mathbf{N}$ & Sub-category & $\begin{array}{l}\text { Number of } \\
\text { articles }\end{array}$ & $\begin{array}{l}\text { Percentage } \\
\text { by sub- } \\
\text { category }\end{array}$ & Reference \\
\hline 1 & $\begin{array}{l}\text { Ontology for modelling product, production } \\
\text { process and equipment (conceptual) }\end{array}$ & 5 & $38,46 \%$ & $\begin{array}{l}{[1][10][11]} \\
{[26][27]}\end{array}$ \\
\hline 2 & $\begin{array}{l}\text { Ontology for modelling product, production } \\
\text { process and equipment (real-life case) }\end{array}$ & 1 & $7,69 \%$ & {$[22]$} \\
\hline 3 & $\begin{array}{l}\text { Ontology for modelling product, production } \\
\text { and assembly processes (conceptual) }\end{array}$ & 5 & $38,46 \%$ & $\begin{array}{ll}{[7][12]} & {[18]} \\
{[21][24]} & \end{array}$ \\
\hline 4 & $\begin{array}{l}\text { Ontology for modelling product, production } \\
\text { and assembly processes (real-life case) }\end{array}$ & 1 & $7,69 \%$ & [25] \\
\hline \multirow[t]{2}{*}{5} & $\begin{array}{l}\text { Ontology for modelling product life cycle } \\
\text { (conceptual) }\end{array}$ & 1 & $7,69 \%$ & [17] \\
\hline & Total & 13 & $\approx 100 \%$ & \\
\hline
\end{tabular}

\section{Discussion and conclusion}

To the best of our knowledge, this study is the first identifiable academic review to classify the literature on integrated product-process models utilizing ontologies. An attempt was made in this paper to develop a classification framework and to use the framework to synthesize what is known in the research and what are the future avenues. We provide a general picture of the past and current literature on the studied topic regarding models' applications, challenges for implementation and approaches to modelling, between 2012-2019. We identified 13 relevant journal papers and conference proceedings. Although we do not claim that the review is exhaustive, it highlights some important implications.

- In our review, we find an increase in the development of conceptual models and the use of ontologies to integrate the product and manufacturing domains. We observe increase in research and published literature in the past couple of years. Our review emphasizes on the importance of models focusing on integrating isolated and uncoupled information that exists within a manufacturing company across different product realisation domains.

- The application and the benefits of the models are many and encompassing at least 4 different areas. In our review, we find that these models' benefits are mostly related to production planning and scheduling (7 papers, $41,17 \%)$. It appears that the models are also important for supporting co-platforming and changeable manufacturing systems (5 papers, $29,41 \%$ ).

- Our review indicates that the researchers agree on the practical challenges for implementation of the integrated product-process models and the development of the ontologies.

- Generally, the integrated product-process models have different approaches to modelling, different viewpoints and level of details. These models often provide partial solutions for specific applications and hence lack comprehensive view. For example, some models are very detailed focusing on specific process domain (e.g. machining), or on the assembly domain while considering the product features and parameters. While other models have a high level of representation of the manufacturing domain including planning and scheduling and therefore better suited for production planning and scheduling applications. 


\section{Limitation of the study}

This paper focused on product-process models that utilizes ontologies. Although other conceptual models for connecting product and manufacturing domains exists and are mentioned for comparison, this paper has primary focused on development of ontologies for describing the two domains and the links between them.

The methodology that is employed in the literature review has some limitations. The first is that the findings are based on data that were collected from academic journals and conferences. The second, the limited number of databases that were included in this paper. In the future, other databases need to be searched for. However, although, this means that the literature review was not exhaustive, it can be regarded as comprehensive where the developed classifications framework can be used to analyse data from other publications. The third possible limitation is associated with the research strategy limited to published papers in English and eight-year time frame between 2012-2019. The fourth limitation has to do with the fact that the decision on selecting published papers for this review was subjective, although the selected papers were reviewed by the co-authors of this papers.

\section{Further research questions and directions}

One of the greatest challenges is to bridge the gap between research ad practitioners. Our literature review shows that;

- Integrated product-process models are mostly conceptual and real-life contexts in which the feasibility of the models is validated are missing. There is a need of empirical studies to support the implementation of such integrated models and carry out pilot test in real-life manufacturing companies.

- Integrated models do not account for the fact that equipment and production processes might be used in relation with other equipment and process in a manufacturing cell or line.

- In general, integrated product-process models lack consideration of manufacturing speed or cost estimations.

- The integrated product-process models based on ontologies are typically static descriptions and lack the life cycle perspective. For example, a resource that is being included in a model may change its conditions, capabilities or parameters. The reviewed papers provided limited information and understanding of how to maintain and modifying such ontology models.

- $\quad$ To keep up with the manufacturing sustainability trends, it would be viable to extend the manufacturing domain to life cycle stages like recycling and dismantling.

\section{References}

[1] T. Brunoe, A. . Andersen, D. Sorensen, K. Nielsen, and M. Bejlegaard, "Integrated product-process modelling for platform-based co-development," Int. J. Prod. Res., 2019.

[2] T. Tolio et al., "SPECIES - Co-evolution of products, processes and production systems," CIRP Ann. - Manuf. Technol., vol. 59, no. 2, pp. 672-693, 2010. 
[3] T. AlGeddawy and H. ElMaraghy, "A model for co-evolution in manufacturing based on biological analogy," Int. J. Prod. Res., vol. 49, no. 15, pp. 4415-4435, 2011.

[4] T. Tolio, M. Sacco, W. Terkaj, and M. Urgo, "Virtual factory: An integrated framework for manufacturing systems design and analysis," Procedia CIRP, vol. 7, pp. 25-30, 2013.

[5] K. Agyapong-Kodua, R. Brown, R. Darlington, and S. Ratchev, "An integrated product-process design methodology for cost-effective product realisation,” Int. J. Comput. Integr. Manuf., vol. 25, no. 9, pp. 814-828, 2012.

[6] M. T. Michaelis, H. Johannesson, and H. A. ElMaraghy, "Function and process modeling for integrated product and manufacturing system platforms," J. Manuf. Syst., vol. 36, pp. 203-215, 2015.

[7] E. Järvenpää, N. Siltala, O. Hylli, and M. Lanz, "The development of an ontology for describing the capabilities of manufacturing resources," J. Intell. Manuf., vol. 30, no. 2, pp. 959-978, 2019.

[8] T. Gruber, "A translation approach to portable ontology specifications," J. Knowl. Acquis., vol. 5, no. 2, pp. 199-220, 1993.

[9] R. Studer, V. R. Benjamins, and D. Fensel, "Knowledge Engineering: Principles and methods," Data Knowl. Eng., vol. 25, no. 1-2, pp. 161-197, 1998.

[10] Brunoe, D. Sorensen, M. Bejlegaard, A. Andersen, and K. Nielsen, "Product-Process Modelling as an Enabler of Manufacturing Changeability," in IFIP International Federation for Information Processing 2018, 2018, vol. 535, no. 1, pp. 328-335.

[11] Brunoe, D. Sørensen, A. Andersen, and K. Nielsen, "Framework for integrating production system models and product family models," Procedia CIRP, vol. 72, pp. 592-597, 2018.

[12] B. R. Ferrer, B. Ahmad, A. Lobov, D. A. Vera, J. L. M. Lastra, and R. Harrison, "An approach for knowledge-driven product, process and resource mappings for assembly automation," IEEE Int. Conf. Autom. Sci. Eng., vol. 2015-Octob, pp. 1104-1109, 2015.

[13] M. Abbas and H. Elmaraghy, "Functional Synthesis of Manufacturing Systems Using Co-Platforming to Minimize Cost of Machines and System Changes," J. Mech. Des. Trans. ASME, vol. 140, no. 2, 2018.

[14] M. Abbas and H. ElMaraghy, "Synthesis and optimization of manufacturing systems configuration using co-platforming," CIRP J. Manuf. Sci. Technol., vol. 20, pp. 51-65, 2018.

[15] M. Abbas and H. Elmaraghy, "Functional Synthesis of Manufacturing Systems Using Co-platforming," Procedia CIRP, vol. 52, pp. 102-107, 2016.

[16] M. Abbas and H. ElMaraghy, "Design synthesis of machining systems using co-platforming," $J$. Manuf. Syst., vol. 41, pp. 299-313, 2016.

[17] S. Li and L. Qiao, "Ontology-based modeling of manufacturing information and its semantic retrieval," Proc. 2012 IEEE 16th Int. Conf. Comput. Support. Coop. Work Des. CSCWD 2012, no. Grant 51075022, pp. 540-545, 2012.

[18] J. Zhang, B. Ahmad, D. Vera, and R. Harrison, "Ontology based semantic-predictive model for reconfigurable automation systems," IEEE Int. Conf. Ind. Informatics, pp. 1094-1099, 2016.

[19] T. Algeddawy and H. Elmaraghy, "Co-evolution hypotheses and model for manufacturing planning," CIRP Ann. - Manuf. Technol., vol. 59, no. 1, pp. 445-448, 2010.

[20] M. T. Michaelis and H. Johannesson, "Platform approaches in manufacturing - Considering integration with product platforms," Proc. ASME Des. Eng. Tech. Conf., vol. 9, no. August, pp. 1115-1124, 2011.

[21] G. Bruno, "Measuring product semantic similarity by exploiting a manufacturing process ontology," Proc. 2015 Int. Conf. Ind. Eng. Syst. Manag. IEEE IESM 2015, no. October, pp. 1251-1257, 2016.

[22] Z. Li, X. Zhou, W. M. Wang, G. Huang, Z. Tian, and S. Huang, “An ontology-based product design framework for manufacturability verification and knowledge reuse," Int. J. Adv. Manuf. Technol., vol. 99, no. 9-12, pp. 2121-2135, 2018.

[23] P. Lumsakul, L. Sheldrick, and S. Rahimifard, "The Sustainable Co-Design of Products and Production Systems," Procedia Manuf., vol. 21, pp. 854-861, 2018.

[24] L. Qiao, Y. Qie, Z. Zhu, Y. Zhu, U. K. uz Zaman, and N. Anwer, "An ontology-based modelling and reasoning framework for assembly sequence planning," Int. J. Adv. Manuf. Technol., vol. 94, no. 9-12, pp. 4187-4197, 2018.

[25] M. Ahmad, B. R. Ferrer, B. Ahmad, D. Vera, J. L. Martinez Lastra, and R. Harrison, "Knowledgebased PPR modelling for assembly automation," CIRP J. Manuf. Sci. Technol., vol. 21, pp. 33-46, 2018.

[26] D. Sorensen, T. Brunoe, and K. Nielsen, "A classification scheme for production system processes," Procedia CIRP, vol. 72, pp. 609-614, 2018.

[27] Y. Zhang, X. Luo, H. Zhang, and J. W. Sutherland, "A knowledge representation for unit manufacturing processes,” Int. J. Adv. Manuf. Technol., vol. 73, no. 5-8, pp. 1011-1031, 2014. 